\title{
Gênese e constituição da terapia ocupacional: em busca de uma interpretação teórico-metodológica
}

\section{Genesis and constitution of occupational therapy: searching a theoretical-methodological interpretation}

\author{
Waldez Cavalcante Bezerra ${ }^{1}$, Rosa Lúcia Prédes Trindade ${ }^{2}$
}

http://dx.doi.org/10.11606/issn.2238-6149.v24i2p155-161

Bezerra WC, Trindade RLP. Gênese e constituição da terapia ocupacional: em busca de uma interpretação teórico-metodológica. Rev. Ter. Ocup. Univ. São Paulo, 2013 maio/ago, 24(2);155-61.

RESUMO: Este artigo problematiza as análises presentes na literatura sobre os fundamentos históricos da Terapia Ocupacional, a partir de um levantamento bibliográfico de obras de relevância para a formação profissional no Brasil, com o intuito de propor uma abordagem teórico-metodológica para o estudo dessa temática. Tomando como base as proposições de Montaño (2007) e Netto (2009) sobre os fundamentos do Serviço Social, sugere-se a existência na Terapia Ocupacional de duas grandes tendências de análise da gênese e constituição da profissão: a endogenista e a histórico-crítica. A partir da compreensão acerca dessas duas perspectivas, defende-se o posicionamento de que elas não se configuram, apenas, como opiniões distintas sobre a origem da Terapia Ocupacional, mas expressam perspectivas díspares que levam a conclusões radicalmente distintas acerca da profissão.

DESCRITORES: Terapia ocupacional; Terapia ocupacional/ história; Terapia ocupacional/tendências.
Bezerra WC, Trindade RLP. Genesis and constitution of occupational therapy: searching a theoretical-methodological interpretation. Rev. Ter. Ocup. Univ. São Paulo, 2013 maio/ ago, 24(2);155-61.

\begin{abstract}
This article problematizes the analysis present in literature about the historical fundaments of Occupational therapy, from a bibliographic raise of relevant papers related to the professional formation in Brazil, aiming to propose a theoreticalmethodological approach for the theme. Basing on Montaño's (2007) and Netto's (2009) proposals about the foundations of Social Service, it is suggested the existence, in Occupational therapy, of two great tendencies for analyzing the genesis and constitution of the profession: the endogenist and the criticalhistorical. From the comprehension of these two perspectives, it is defended the positioning that them both do not configure, only, as distinct opinions about the origins of Occupational Therapy, they express different perspectives which lead to radically different conclusions about the profession.
\end{abstract}

KEYWORDS: Occupational therapy; Occupational therapy/ history; Occupational therapy/tendencies.

\footnotetext{
1. Terapeuta Ocupacional, Mestre em Serviço Social pela UFAL, Integrante do Grupo de Pesquisa "Serviço Social, Trabalho e Políticas Sociais" da UFAL e do Grupo de Pesquisa "Saúde Mental e Saúde Coletiva" da UNCISAL, Professor do curso de Terapia Ocupacional da Universidade Estadual de Ciências da Saúde de Alagoas, UNCISAL, Maceió, Alagoas, Brasil.

2. Assistente Social, Pós-Doutora pelo Programa de Pós-Graduação em Sociologia e Antropologia da UFRJ, Doutora em Serviço Social pela UFRJ, Professora Adjunta da Graduação e da Pós-Graduação em Serviço Social da UFAL, Líder do Grupo de Pesquisa "Serviço Social, Trabalho e Políticas Sociais" da UFAL, Faculdade de Serviço Social, Universidade Federal de Alagoas - UFAL, Maceió, Alagoas, Brasil.

Endereço para correspondência: Waldez C. Bezerra - Rua Magda Danielle, 160, Tabuleiro. CEP: 57082-116. Maceió, AL. Email: waldezto@yahoo.com.br
} 


\section{INTRODUÇÃO}

$£ \begin{aligned} & \text { este artigo, pretende-se refletir sobre } \\ & \text { a gênese e a constituição da Terapia } \\ & \text { Ocupacional, a partir das análises realizadas }\end{aligned}$ acerca do tema na literatura profissional, com o intuito de propor uma abordagem teórico-metodológica para o estudo dos fundamentos históricos da profissão. Para tanto, realizou-se uma pesquisa bibliográfica com o objetivo de conhecer as produções que são referências na temática e que tem forte influência na formação profissional no Brasil.

A produção sobre a origem da Terapia Ocupacional pode ser analisada a partir da categorização elaborada por Montaño ${ }^{1}$, para a profissão de Serviço Social, a saber: as perspectivas endogenista e histórico-crítica. Outro conceito incorporado para esta análise foi o de protoformas de $\mathrm{Netto}^{2}$.

Contudo, a utilização dessas categorias não significa uma transposição mecanicista da análise sobre o Serviço Social para a Terapia Ocupacional. Apenas percebeu-se a possibilidade de uso dos conceitos desta área, com as mediações necessárias, para se refletir sobre a Terapia Ocupacional, guardadas as devidas diferenças entre as profissões.

As reflexões aqui contidas são parte da dissertação A Terapia Ocupacional na sociedade capitalista e sua inserção profissional nas políticas sociais no Brasil, apresentada ao Programa de Pós-Graduação em Serviço Social da Universidade Federal de Alagoas, em setembro de 2011. Acredita-se que tais questões podem contribuir para o debate profissional sobre a origem da Terapia Ocupacional e preencher possíveis lacunas teóricas.

\section{AS TESES DE MONTAÑO E SUAAPLICABILIDADE NA TERAPIA OCUPACIONAL}

Montaño", em "A natureza do serviço social”, analisou os fundamentos do Serviço Social a partir do estudo das principais obras que buscaram explicar a origem e a natureza da profissão. Nesta análise, endogenismo caracteriza a vertente analítica que desconsidera a história da sociedade como o fundamento e a causalidade da gênese e desenvolvimento profissional, apenas situando as etapas do Serviço Social em seu desenvolvimento cronológico, sendo a gênese da profissão considerada uma evolução das formas anteriores de ajuda. Opondo-se à perspectiva endogenista, Montãno ${ }^{1}$ identifica a perspectiva históricocrítica, na qual se incluem os autores que vão analisar o Serviço Social como uma resultante das relações sociais próprias do capitalismo monopolista, no contexto em que o Estado toma para si a responsabilidade pelas respostas à questão social ${ }^{(1)}$ e requisita profissionais qualificados que irão contribuir, por meio de sua intervenção, com o processo de reprodução social.

Baseado nessas proposições, é possível identificar também estas duas perspectivas na literatura da Terapia Ocupacional. Desse modo, a perspectiva endogenista incluí os autores que compreendem a Terapia Ocupacional a partir de uma evolução que desconsidera o processo histórico com seus aspectos econômicos, políticos e sociais - como determinante do surgimento e desenvolvimento da profissão. Nesses autores, observa-se a existência de uma autonomia da profissão com relação à base material da sociedade, de modo que as transformações das condições objetivas de vida parecem não interferir em seus rumos. Nessa linha de análise, a profissão teria seu "início" com a utilização da atividade nas práticas de cuidado em saúde e, sendo a Terapia Ocupacional uma continuidade dessas práticas. Agindo assim, tais autores remetem a origem profissional ao passado remoto, como por exemplo, à Grécia Antiga, para justificar a Terapia Ocupacional, tal como a conhecemos. Essa perspectiva tem como expoentes, autores influentes na Terapia Ocupacional brasileira e internacional, como Benetton $^{3}$, Francisco ${ }^{4}$, Hagedorn ${ }^{5}$ e Schwartz ${ }^{6}$.

O trecho abaixo ilustra a visão endogenista para apresentar a origem da Terapia Ocupacional:

\begin{abstract}
"Muito se tem falado da terapia ocupacional como uma profissão nova, entretanto a idéia de que a ocupação ou diversão de qualquer espécie é benéfica aos doentes manifesta-se de tempos em tempos na história da humanidade. Observamos historicamente que a ocupação como meio de tratamento remonta às civilizações clássicas. Os jogos, a música e os exercícios físicos foram utilizados por gregos, romanos e egípcios como medida de tratamento do corpo e da alma"4 (p.22).
\end{abstract}

De acordo com esta postura, a constituição da profissão está relacionada ao reconhecimento científico da utilização da ocupação com fins terapêuticos. Assim, a origem da profissão manteria relação com as práticas anteriormente desenvolvidas ao longo da história da humanidade, de modo que, as primeiras décadas do

(1) Por questão social entende-se o conjunto das expressões das desigualdades da sociedade capitalista madura, que tem uma raiz comum: a produção social é cada vez mais coletiva, o trabalho torna-se mais amplamente social, enquanto a apropriação dos seus frutos mantémse privada, monopolizada por uma parte minoritária da sociedade. Assim, a questão social está vinculada ao conflito capital e trabalho ${ }^{16}$. 
século XX somente marcariam o "inicio formal da Terapia

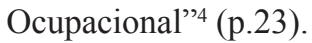

Hagedorn 5 , em "Fundamentos da Prática em Terapia Ocupacional”, coloca que a Terapia Ocupacional tem sua origem no século XVIII - com o tratamento moral -, mas foi somente no inicio do século XX que se deu sua articulação propriamente dita, quando um grupo heterogêneo de profissionais, nos Estados Unidos, desenvolveu os conceitos de ocupação como instrumento curativo. As proposições dessa autora não fazem referência ao contexto histórico-social como determinante da profissão, e indica que a "criação" da Terapia Ocupacional deu-se, unicamente, pela iniciativa de determinado grupo de indivíduos engajados em provar o poder terapêutico da atividade.

Semelhante análise, porém mais explicitamente focalizada, é a de Schwartz ${ }^{6}$ que ao retomar a origem da Terapia Ocupacional faz referência às personalidades que a autora chama de "fundadores da Terapia Ocupacional", tais como William Rush Dunton, Herbert J. Hall, Eleanor Clarke Slagle, Susan Johnson, Thomas Kidner, George Barton e Susan Tracy, reforçando um caráter personalista na gênese da profissão.

Nessa perspectiva, se nota que a história da profissão é contada a partir dos feitos de determinados indivíduos que deram sua contribuição para a origem e desenvolvimento da Terapia Ocupacional, como se a iniciativa desses sujeitos não fosse uma expressão do que era demandado socialmente, em determinado momento da história. Nesse sentido, a constituição da profissão estaria relacionada, exclusivamente à aplicação de atividades com fins terapêuticos, o que encobre as funções de cunho político-ideológico e econômico, exercidas pela profissão no cerne da sociedade capitalista, já tratadas por Soares? Lopes $^{8}$, Medeiros ${ }^{9}$ e Bezerra e Trindade ${ }^{10}$.

Concorda-se com Mângia ${ }^{11}$ quando coloca que a busca de legitimidade da prática profissional a partir do princípio terapêutico da atividade constitui um equívoco que tem como conseqüência a supervalorização de aspectos psicológicos e o esvaziamento da dimensão histórica e social das práticas profissionais.

Nascimento ${ }^{12}$ também já problematizou essa busca desistoricizada da essência da Terapia Ocupacional a partir do princípio terapêutico da atividade, dotando esta de um caráter quase sagrado que a transforma naquilo que a autora denomina de "mito da atividade terapêutica".

Por outro lado, é possível também encontrar teóricos que buscam compreender a Terapia Ocupacional inserida no contexto das contradições próprias da sociedade capitalista, e por esta razão podem ser situados na perspectiva histórico-crítica, pois, como afirma Montaño ${ }^{1}$, trata-se de entender a profissão como um

"produto da síntese dos projetos político-econômicos que
operam no desenvolvimento histórico, onde se reproduz
material e ideologicamente a fração de classe hegemônica,
quando no contexto do capitalismo monopolista o Estado
toma para si as respostas à 'questão social"”. (p.30)
[Grifos do autor].

$\mathrm{Na}$ Terapia Ocupacional, situam-se nesta perspectiva as autoras: Soares ${ }^{7}$, Medeiros $^{9}, \operatorname{Lopes}^{8}$, Ferrigno $^{13}$ e Magalhães ${ }^{14}$.

Nessas autoras, identifica-se argumentos que reforçam a crítica ao endogenismo, já que parte da literatura profissional desconsidera que a origem da Terapia Ocupacional foi resultado do desenvolvimento econômico, num contexto particular, que demandou aumento de mãode-obra e da especialização do trabalho no capitalismo, com o objetivo de manter e aprimorar essa sociabilidade. Medeiros ${ }^{9}$ afirma:

"Assim é que, ao retomar a história nesta perspectiva, e daí resgatar-lhe a 'herança perdida' da profissão, não se assinalam as diferenças e as contradições existentes nas condições concretas em que a profissão foi produzida; e tampouco analisam-se as questões de saúde e doença como decorrentes de uma sistematização conceitual da normatividade social. A ciência não existe por si, mas é criada por uma comunidade de homens, determinada e concreta"9 (p.134).

Destaca-se que a análise histórico-crítica exige que se considere um conceito fundamental para apreender a função social da profissão: o de reprodução social. Este, na tradição marxista, refere-se ao modo como as relações sociais são produzidas e reproduzidas em sociedade. Segundo Iamamoto e Carvalho ${ }^{15}$, a reprodução das relações sociais é entendida como a reprodução da totalidade da vida social, o que engloba, não apenas, a reprodução da força viva de trabalho e dos meios objetivos de produção, mas também a reprodução espiritual da sociedade e das formas de consciência social, através das quais o homem se posiciona na vida social.

Desse modo, o movimento de desvendar a inserção da Terapia Ocupacional nas relações sociais implica na análise do papel da profissão na reprodução social, uma vez que, ao intervir sobre os problemas originados da exploração do trabalho na produção capitalista, principalmente os relacionados à saúde, o terapeuta ocupacional contribui para a recuperação da força de trabalho, ou seja, para a reprodução da base de sustentação do capital, uma vez que 
é a força de trabalho, em atividade, que gera a mais-valia capitalista $^{7,10}$.

Constata-se também que a análise da Terapia Ocupacional, na perspectiva histórico-crítica, possibilita entender que a ação profissional, ao ser mediada pelas políticas e pelos serviços sociais e desenvolvida em instituições, é necessariamente permeada pelas contradições que atravessam essas políticas, serviços e instituições. Tendo em vista que essas instâncias se configuram como expressões das respostas do Estado às reivindicações dos trabalhadores e às necessidades de reprodução do capital, a ação do terapeuta ocupacional é perpassada por interesses de classes sociais antagônicas e em relação, não podendo ser pensada fora dessa trama, já que a mesma surge como parte das iniciativas sociais que interferem no enfrentamento desses conflitos de classe ${ }^{10}$.

A partir da compreensão dessas duas perspectivas de análise da gênese da profissão (endogenista e históricocrítica), defende-se o posicionamento de que as mesmas não se configuram, apenas, como opiniões distintas sobre a origem da Terapia Ocupacional, que podem ser conciliadas num ecletismo teórico-metodológico. Considera-se que ambas expressam análises teórico-metodológicas díspares, que levam a conclusões radicalmente distintas acerca dos determinantes da gênese e da constituição da profissão.

\section{A CONCEPÇÃO DE PROTOFORMAS COMO POSSIBILIDADE DE SUPERAÇÃO DO ENDOGENISMO}

Para $\mathrm{Netto}^{2}$, a constituição de um novo agente profissional ocorre por meio da refuncionalização de referências e práticas preexistentes, assim como pelas formas institucionais e organizacionais a elas vinculadas. Ao se conformar as práticas e referências desse novo agente, nem sempre esse processo implica a supressão das ideias e dos suportes institucionais e organizativos anteriores, podendo estes serem conservados por um longo período.

Essa concepção pode ajudar a não cair no mesmo equívoco das análises endogenistas sobre a Terapia Ocupacional e fornecer elementos para perceber as linhas de continuidade e ruptura da profissão com as práticas que utilizavam a atividade no cuidado à saúde, já existentes no momento de gênese da Terapia Ocupacional. Por isso, àquilo a que a literatura profissional comumente denomina como "movimentos precursores" da Terapia Ocupacional, aqui são denominadas de protoformas da profissão, apoiados nas análises de Netto ${ }^{2}$.

Sabe-se que a utilização da atividade nas práticas de saúde pode ser observada desde a Antiguidade. Segundo
Benetton $^{3}$, nesse período, as doenças físicas e mentais eram entendidas como males do espírito, sendo as atividades utilizadas com o objetivo de afastar os "maus espíritos", criar um ambiente tranqüilo e facilitar uma aproximação do indivíduo com os deuses. Eram vistas como meios de distração, alívio do sofrimento físico ou mental, podendo provocar certas emoções e serem benéficas ou prejudiciais no processo de cura.

Assim, por muito tempo, a utilização das atividades no cuidado à saúde ocorreu de modo indiferenciado, sem privilégio de qualquer atividade específica. A partir do século XVIII são enfatizadas as práticas terapêuticas que utilizavam o trabalho, principalmente nos serviços de atenção psiquiátrica, tendo em vista a sua função social na nova forma de organizar a produção, sob os moldes capitalistas ${ }^{9}$. Estas práticas receberam várias denominações, dentre elas, tratamento moral, ergoterapia e laborterapia, e, de modo geral, tinham como objetivo a adequação dos doentes ao ambiente asilar e a manutenção institucional através do trabalho dos internos.

Magalhães ${ }^{14}$ afirma que essas práticas surgiram como uma tentativa de coibir os riscos sociais, provocados pela doença e miséria, na Europa, e se caracterizaram como um divisor de águas entre as práticas organizadas de assistência e os serviços fortuitos anteriores, e comportavam um aspecto que transformava as relações entre as autoridades sanitárias e seus assistidos: a descoberta do valor do trabalho sistemático, como forma de controle e terapia.

Nesse período, a valorização do uso da atividade, principalmente o trabalho, no tratamento de doentes mentais foi parte da ideologia da nascente burguesia pós-revolução francesa, que defendia concepções de normalidade e anormalidade ligadas à produtividade, nos termos da economia capitalista9.

Após esse período, observa-se a decadência de valorização dessas práticas provocada pela influência da racionalidade positivista no pensamento científico e pela busca por métodos anatomofisiológicos e farmacológicos de intervenção. Somente no contexto da crise capitalista, no inicio do século XX, que culminou com a Primeira Guerra Mundial, e com o avanço da industrialização, houve a retomada do emprego da ocupação no tratamento, principalmente em reabilitação física, mas agora com um novo significado e cumprindo uma nova função político-ideológica e econômica para o capital. Foi nesse momento que surgiu a Terapia Ocupacional como profissão, emergindo como um novo agente profissional, e incorporando elementos preexistentes das práticas sociais que lhe antecederam ${ }^{9,10}$.

Desse modo, compreende-se que foram as mudanças 
na base material da sociedade que demandaram a emergência de profissões que respondessem, através de serviços sociais, a algumas reivindicações dos trabalhadores e possibilitassem a reprodução da sociedade regida pelo capital. Assim, uma análise crítica sobre a origem histórica da Terapia Ocupacional requer, necessariamente, a inserção dela na totalidade social e a análise das determinações econômicas, políticas e sociais que possibilitaram a sua emergência enquanto profissão.

Portanto, não se pode dizer que a presença da atividade nas práticas de saúde deu-se de modo indiferenciado na Antiguidade, Idade Média e no início do século XVIII, momento de consolidação do capitalismo. $\mathrm{O}$ vínculo de continuidade entre essas práticas está na crença do poder terapêutico da atividade, contudo essas práticas, a partir do século XVIII, começam a cumprir uma funcionalidade política e econômica para o capitalismo, perdendo seu vínculo com as questões metafísicas e espirituais e, por este motivo, o trabalho ganhou lugar de destaque ${ }^{9,10}$.

É possível afirmar que não são todas as práticas que utilizavam a atividade na saúde - anteriores à emergência da Terapia Ocupacional -, que podem ser chamadas de protoformas da profissão, mas, somente, aquelas a partir do século XVIII, por já possuírem uma diferenciação em relação às práticas anteriores, na medida em que visavam a atender a algumas necessidades do capitalismo emergente, mas que, ainda não se configuram como a profissão Terapia Ocupacional, uma vez que esta última está atrelada a ação do Estado ante a questão social, mais especificamente frente aos problemas da relação saúde e trabalho, no contexto do capitalismo dos monopólios, momento este de surgimento de várias profissões sociais e da saúde(2)

Ressalta-se que toda profissão surge para atender a necessidades sociais, originadas do processo histórico. No que diz respeito à Terapia Ocupacional, pode-se dizer que essa necessidade surgiu com a Primeira Guerra Mundial e com a intensificação do processo de industrialização fordista, no inicio do século XX. Naquele período, cresceu o número de pessoas acidentadas, gerando uma carência de força de trabalho produtiva, e a desqualificação do trabalho provocada pelo fordismo possibilitou a absorção de deficientes físicos e sensoriais na linha de montagem da indústria moderna $a^{7,10}$.

A Terapia Ocupacional emerge socialmente não só para tratar das vítimas dos acidentes de trabalho da indústria moderna, mas também para colocar em condições de exploração os indivíduos que, por alguma problemática física e/ou sensorial, encontravam-se à margem da produção capitalista ${ }^{7}$.

Dessa forma, o caminho para a profissionalização também marca uma relação de ruptura com as práticas já existentes, que se coloca como decisiva para a constituição da Terapia Ocupacional enquanto profissão. Essa ruptura é caracterizada pelo momento no qual os agentes profissionais são inseridos em ações interventivas, cuja dinâmica, organização, recursos e objetivos já não são determinados completamente pelo seu controle. Assim, a profissão não pode ser vista como continuidade das práticas anteriores de utilização da atividade no cuidado em saúde, tendo em vista que as mudanças sociais ocorridas no capitalismo e as novas necessidades do Estado demandaram a emergência desse profissional, na condição de assalariado, como integrante do corpo de funcionários do Estado para atender aos interesses monopolistas.

Magalhães ${ }^{14}$ afirma que até o fim da Idade Média a enfermidade era atribuída a causas sobrenaturais, o que justifica sua relação com práticas religiosas. O cuidado dos doentes era realizado por familiares ou escravos, quando em domicílio, e por monges, freiras e sacerdotes, quando executados em espaços institucionais, o que leva a crer que essas atividades eram realizadas sem remuneração e desprovidas de prestígio ou valor econômico.

É importante ressaltar que pode haver semelhanças entre essas práticas e a Terapia Ocupacional, principalmente quanto ao uso da atividade como recurso terapêutico, o que pode resultar numa ideia aparente de continuidade. Contudo, essas semelhanças apenas escamoteiam a ruptura que marca o surgimento da profissão com uma significação social própria do período monopolista: a de contribuir diretamente para a reprodução da força de trabalho no contexto de expansão da indústria moderna.

Portanto, se pode afirmar que foi a legitimidade conferida à Terapia Ocupacional pelo Estado monopolista no inicio do século XX, por meio da criação e expansão das políticas sociais, que ocorreu a abertura de um espaço para este profissional no mercado de trabalho, possibilitando sua profissionalização, institucionalização e reprodução ao longo do desenvolvimento capitalista ${ }^{10}$.

É importante notar que se a profissão fosse apenas uma continuidade das práticas psiquiátricas do tratamento

(2) De acordo com Netto ${ }^{2}$ o surgimento das profissões no monopolismo dá-se a partir da refuncionalização de práticas anteriores, para atender às novas exigências da dinâmica dos monopólios, quando o Estado passa a intervir sobre a questão social através de políticas sociais, ocorrendo, deste modo, a imbricação de suas funções econômicas diretas e indiretas, necessárias à expansão do capital. 
moral e suas derivações, teria se restringido às ações na área de saúde mental, entretanto, o que se notou foi que a emergência e a institucionalização da profissão deram-se a partir dos serviços de reabilitação profissional, principalmente para tratar deficientes físicos com o intuito de (re)inserí-los como força de trabalho na indústria fordista. A partir desse raciocínio, é possível entender que o maior desenvolvimento da profissão nas ações de reabilitação física não é uma interrupção do seu curso evolutivo, supostamente iniciado nas práticas de saúde mental. Isso vem mostrar que foram interesses específicos do desenvolvimento capitalista, que requereram ações do Estado, em articulação com a indústria moderna, envolvendo ações voltadas para a reabilitação da força de trabalho em favor do mercado ${ }^{9,10}$.

Assim, na origem da Terapia Ocupacional recorreuse às referências já construídas nas práticas anteriores vinculadas à atividade (expressão de continuidade), consideradas aqui como as protoformas da profissão, mas a origem da mesma constitui um novo fenômeno que vem a atender a novas exigências de um momento histórico específico ao desenvolvimento capitalista (expressão da ruptura).

\section{CONCLUSÃO}

Portanto, apoiados em Montaño ${ }^{1}$ sugere-se a existência na Terapia Ocupacional de duas grandes tendências de análise da gênese e constituição da profissão: a endogenista e a histórico-crítica. Contudo, acredita-se que a análise da Terapia Ocupacional requer, necessariamente, considerar a sua inserção na sociedade e que somente desse modo as demandas e atribuições profissionais ganham sentido. Reforça-se que a Terapia Ocupacional só existe em condições e relações sociais historicamente determinadas, e que a mesma, por ser uma instituição componente da realidade, é uma síntese de múltiplas determinações.

Fica evidente que análises endogenistas apresentam limites teóricos para se apreender a relação existente entre a Terapia Ocupacional e as mudanças societárias, sejam elas no âmbito do trabalho, do Estado ou das políticas sociais. Para o avanço de uma produção crítica na área, é necessário ultrapassar as fronteiras internas da Terapia Ocupacional para situá-la no contexto das relações sociais mais amplas que configuram a sociedade capitalista, mais especificamente, no contexto em que o Estado monopolista toma a questão social, e suas expressões, como alvo de sua intervenção.

O intuito com as reflexões aqui apresentadas foi contribuir com os esforços já consolidados, no sentido de romper com a postura endogenista na análise da profissão. Daí porque, é necessário captar as contradições imanentes à realidade social e examinar os caminhos da profissão atentando para as razões político-econômicas a ela subjacentes e evitar que a discussão seja esvaziada das tensões societárias que marcaram o surgimento e desenvolvimento da Terapia Ocupacional.

\section{REFERÊNCIAS}

1. Montãno C. A natureza do serviço social. São Paulo: Cortez; 2007.

2. Netto JP. Capitalismo monopolista e Serviço Social. 7a ed. São Paulo: Cortez; 2009.

3. Benetton J. Trilhas associativas: ampliando recursos na clínica da psicose. São Paulo: Lemos Editorial; 1991.

5. Hagedorn, R. Fundamentos da Prática em Terapia Ocupacional. São Paulo: Dynamis Editorial, 1999.

6. Schwartz KB. História e tendência da prática no tratamento da disfunção física. In: Pedretti LW, Early MB. Terapia ocupacional: capacidades práticas para as disfunções físicas. 5a ed. São Paulo: Roca; 2004.

7. Soares LBT. Terapia ocupacional: lógica do capital ou do trabalho? São Paulo: Hucitec; 1991.

4. Francisco BR. Terapia Ocupacional. 2a ed. Campinas: Papirus; 2001.

8. Lopes RE. A cidadania, políticas públicas e terapia ocupacional, no contexto das ações de saúde mental e saúde da pessoa portadora de deficiência no município de São Paulo [tese]. Campinas: Faculdade de Educação, Universidade Estadual de Campinas; 1999. Disponível em: http://www.bibliotecadigital. unicamp.br/document/?code=vtls000184393

9. Medeiros MHR. Terapia ocupacional: um enfoque epistemológico e social. São Paulo: Hucitec, EdUFSCAR; 2003.

10. Bezerra WC, Trindade RLP. A terapia ocupacional na sociedade capitalista e sua inserção profissional nas políticas sociais no Brasil. Cad Ter Ocup UFSCar, São Carlos. 2013;21(2):429-37. 
Bezerra WC, Trindade RLP. Gênese e constituição da terapia. Rev. Ter. Ocup. Univ. São Paulo, 2013 maio/ago, 24(2);155-61.

http://dx.doi.org/10.4322\%2Fcto.2013.045

11. Mângia EF. Apontamentos sobre o campo da terapia ocupacional. Rev Ter Ocup Univ São Paulo. 1998;9(1):5-13.

12. Nascimento BA. O mito da atividade terapêutica. Rev Ter Ocup Univ São Paulo. 1990;1(1):17-21. Disponível em: http:/ disciplinas.stoa.usp.br/pluginfile.php/23825/mod_resource/ content/1/mitodaatividadeterapeutica.pdf

13. Ferrigno ISV. Terapia Ocupacional: considerações sobre o contexto profissional. Rev Ter Ocup Univ São Paulo. 1991;2(1):3-11.

Recebido para publicação: 07/03/2013

Aceito para publicação: 21/06/2013
14. Magalhães LV. Os terapeutas ocupacionais no Brasil: sob o signo da contradição [dissertação]. Campinas: Faculdade de Educação, Universidade Estadual de Campinas; 1989. Disponível em: http://www.bibliotecadigital.unicamp.br/ document $/$ ?code $=$ vtls 000018172

15. Iamamoto MV, Carvalho R. Relações sociais e serviço social no Brasil: esboço de uma interpretação histórico-metodológica. 21a ed. São Paulo: Cortez, CELATS; 2007.

16. Iamamoto MV. O Serviço Social na contemporaneidade: trabalho e formação profissional. 3a ed. São Paulo: Cortez; 2000. 